\title{
Farmers' Own Research: Organic Farmers' Experiments in Austria and Implications for Agricultural Innovation Systems
}

\author{
Susanne Kummer ${ }^{1}$, Friedrich Leitgeb ${ }^{1} \&$ Christian R. Vogl $^{1}$ \\ ${ }^{1}$ Division of Organic Farming, Department of Sustainable Agricultural Systems, University of Natural Resources \\ and Life Sciences Vienna, Austria \\ Correspondence: Susanne Kummer, University of Natural Resources and Life Sciences Vienna (BOKU), \\ Gregor-Mendel-Strasse 33, A-1180 Vienna, Austria. E-mail: susanne.kummer@boku.ac.at
}

Received: November 22, 2016 Accepted: December 15, 2016 Online Published: January 12, 2017

doi:10.5539/sar.v6n1p103

URL: http://dx.doi.org/10.5539/sar.v6n1p103

\begin{abstract}
Farmers' experiments can be defined as the autonomous activities of farmers to try or introduce something new at the farm, and include evaluation of success or failure with farmers' own methods. Experiments enable farmers to adapt their farms to changing circumstances, build up local knowledge, and have resulted in countless agricultural innovations. Most research on the topic has been conducted in countries of the south. In this paper, however, we present experiments of randomly sampled organic farmers in Austria, and we discuss implications for agricultural innovation systems. In 76 structured questionnaire interviews we investigated topics, motives, methods and outcomes of farmers' experiments, and factors related to the frequency of experimentation. From the interviewed farmers, $90 \%$ reported experiments, and the majority of experiments (94\%) involved monitoring and evaluation strategies. Farmers who reported a high frequency of experimentation showed a significantly higher propensity to plan, document and repeat their experiments, and had a more positive attitude towards experimenting than farmers that rarely experimented. We conclude that experimenting is a common activity among organic farmers in Austria, and that farmers have their own methods to conduct and assess their experiments. The most significant outcome is the creation of new knowledge, stressing the importance of experimentation for learning and adaptive farm management. Farmers' experiments are significant on two levels, i.e. at individual farm level and at the level of agricultural innovation systems. Taking full advantage of this innovative potential requires a better involvement of farmers as co-researchers into the development of agricultural innovations.
\end{abstract}

Keywords: adaptive management, European Innovation Partnership, farmer innovation, farmer learning, knowledge exchange, local innovation, local knowledge, organic agriculture, participatory research

\section{Introduction}

The historical development of locally adapted farming systems worldwide can be ascribed to continuous autonomous experimentation activities of farmers (Hoffmann, Probst, \& Christinck, 2007). Experimenting enables farmers to adapt to constantly changing conditions (Bentley, 2006; Darnhofer, Bellon, Dedieu, \& Milestad, 2010), is a means to generate local knowledge (Sumberg \& Okali, 1997), and builds the base for countless agricultural innovations. The potential of farmers' experiments to contribute to agricultural development has not been taken into consideration by agricultural scientists for a long time. Only a small group of anthropologists and agricultural historians have shown interest in the topic in the past (Johnson, 1972; Sumberg \& Okali, 1997). With the relatively recent interest in rural development including the concepts of participation, empowerment and sustainability, farmers' experiments and local knowledge began to attract more attention within research, especially in the context of development studies (Bentley, van Mele, \& Acheampong, 2010; Sumberg, Okali, \& Reece, 2003).

Scientific research about farmers' experiments mainly focused on case studies set in development contexts in countries of the South, especially in Asia, Africa and Latin America (Chambers, Pacey, \& Thrupp, 1998; Haverkort, van der Kamp, \& Waters-Bayer, 1991; Reij \& Waters-Bayer, 2001b; Sturdy, Jewitt, \& Lorentz, 2008; Laurens van Veldhuizen, Waters-Bayer, Ramírez, Johnson, \& Thompson, 1997), and little has been written about the situation in so called industrialized countries (Kandel, Porter, Carr, \& Zwinger, 2008; Kummer, 2011; McKenzie, 2013). Furthermore, few research activities investigated farmers' experiments in a systematic way, by 
studying the entire process of experimentation and the applied methods. Literature on farmers' experiments mainly focused on few examples (Bentley, 2006) of active experimenters within the farming community (Haverkort et al., 1991; Reij \& Waters-Bayer, 2001b), outstanding 'research-minded farmers' (Biggs, 1990) and 'farmer innovators' (Critchley, 2000; Reij \& Waters-Bayer, 2001a), and most presented experiments concerned plant production issues (Sumberg \& Okali, 1997; van Veldhuizen, Waters-Bayer, Ramirez, Johnson, \& Thompson, 1997). Furthermore, most sources refer to experiments carried out in the context of participatory research (Bentley et al., 2010; Kandel et al., 2008; Wortmann et al., 2005), i.e. experiments together with researchers and extensionists and not independent farmers' experimentation. Consequently, our research aims at filling the knowledge gap on farmers' autonomous experiments in a 'non-development' context.

Case studies of smallholder farmers in the Global South emphasize the need and creative capacity of finding appropriate solutions within conditions of resource scarcity (Leitgeb, Kummer, Funes-Monzote, \& Vogl, 2014) and poverty (Reij \& Waters-Bayer, 2001a). It is a powerful motive to try a new idea when 'farmers are driven by the need to feed their families' (Reij \& Waters-Bayer, 2001a, p.83). Although the situation in less constrained conditions will be less threatening and so the urgency involved in experimenting is presumably lower, the overarching significance of experimentation is still the same: Farmers, no matter in which part of the earth, have always lived in changing environments where uncertainty and disturbances are inevitable. Therefore, farmers need the ability to adapt to change in order to be able to maintain their farms. Experimenting is one way for farmers to learn, and is a key strategy to adapt to change and thus enhance adaptive management of a farm. Conducting and monitoring experiments allows a better understanding of system dynamics, widens the range of options in case of change, and enables farmers to improve their management practices based on the knowledge gained (Darnhofer et al., 2010). The outcome of the iterative process of adaptive management is learning about the farming system, i.e. an ongoing reconsideration of the efficiency of measures taken, the accuracy of the consequences of actions, the relationship between actions and indicators, and learning about trade-offs (Milestad, Dedieu, Darnhofer, \& Bellon, 2012).

Besides the significance of experimentation for adaptive management of farms in general, there are two reasons why it is particularly interesting to explore farmers' experiments in the context of organic agriculture. First, sustainable land use practices are more knowledge-intensive (Röling \& Brouwers, 1999). While conventional farmers can use external inputs such as synthetic pesticides and synthetic fertilizers to handle adverse dynamics in their agro-ecosystem, organic farmers need to develop knowledge about the agro-ecosystem to a larger extent to be able to manage their farms successfully without these inputs. Second, organic agriculture was developed by farmers' grassroots organizations, where farmers themselves were responsible for advances and innovations. Official research and extension only played a minor role in the development of organic agriculture (Brunori et al., 2013; Padel, 2001), and so organic agriculture developed by practical experiments and trials of farmers and practical researchers. The lack of advice and formal research in the initial phase of organic agriculture leads to the assumption that organic farmers have developed a culture of experimentation (Gerber, Hoffmann, \& Kügler, 1996).

\subsection{Defining Farmers' Experiments}

Farmers' experiments can be defined as the activity of trying or introducing something totally or partially new at the farm, including evaluation of the success or failure of this introduction (Quiroz, 1999), or as the comparison of something known with something unknown (Stolzenbach, 1999). Sumberg and Okali (1997) consider two conditions necessary for an activity to be labeled an experiment: the creation or initial observation of conditions, and the observation or monitoring of subsequent results.

A common concept of on-farm experimentation is 'on-farm research', which means research conducted, and usually also controlled, by scientists on farms, involving the farmer more or less actively (Lawrence, Christodoulou, \& Whish, 2007). Another term used in literature is 'farmer-initiated research', which refers to 'research conducted by farmers for discovery or production of information' (Wortmann et al., 2005, p.244) in cooperation with research and extension. In this study, however, we focus on experiments carried out by farmers on their own initiative, and we explicitly do not refer to on-farm research. Farmers themselves often do not use the term 'experiment' to refer to their practical on-farm experiments (Stuiver, Leeuwis, \& van der Ploeg, 2004), but relate this term more to a scientific and formal procedure. In various empirical studies on the topic, the term 'trying' instead of 'experimenting' has been perceived as being more appropriate (Sumberg \& Okali, 1997), while in other cases local terms were used to address the subject in the field (Stolzenbach, 1999).

We conceptualize farmers' experiments as individual research processes with a certain problem or topic as starting point, the experiment itself involving methods to conduct and monitor the process, and different possible 
outcomes that can be classified into: i) adaptations of a method or practice, ii) local innovations (i.e., innovations that are not new in general but to the specific area or context), iii) inventions and iv) failures (i.e., experiments that do not lead to satisfactory results). Experiments are influenced by various intervening factors such as environmental, social and personal conditions (Leitgeb et al., 2014; Sumberg \& Okali, 1997), and are embedded into the wider agricultural communication and innovation system (Leitgeb, Funes-Monzote, Kummer, \& Vogl, 2011).

\subsection{Positioning Farmers' Experiments within Agricultural Innovation Systems}

An agricultural innovation system (AIS) consists not only of actors directly involved in the agricultural production chain and the agricultural research, extension and education system, but of a diversity of stakeholders within and outside the agricultural sector that are involved in the development of agricultural innovations (Hermans, Klerkx, \& Roep, 2015). In contrast to the overcome linear 'transfer of technology' approach where innovations were seen as being exclusively developed by science and then transferred to farmers that were expected to adopt them, the AIS perspective considers the development of innovation as co-evolutionary process shaped by all actors involved (Klerkx, van Mierlo, \& Leeuwis, 2012), and includes institutional and political dimensions (Schut, Rodenburg, Klerkx, van Ast, \& Bastiaans, 2014). The main focus is on learning as a means of developing new arrangements specific to local contexts, and on strengthening the capacity of actors to create, diffuse and use knowledge and enable innovation (Rivera \& Sulaiman, 2009), and so consequently the role of farmers as innovators and the value of local knowledge receives more attention (Brunori et al., 2013).

The shift to a systemic perception on innovation development also displays within the Common Agricultural Policy (CAP) of the European Union: A current program of the European Commission is the 'European Innovation Partnership on Agricultural Productivity and Sustainability' (EIP-AGRI). The proposed EIP-AGRI stresses the importance of innovation and knowledge exchange in the agrarian sector to meet societal challenges of food production, and emphasizes the need for systemic feedback from practice to science, for enhancing knowledge exchange, and for joint efforts to invest in sustainable innovation (European Commission [EC], 2012).

In the context of this current EIP-AGRI it is relevant to investigate, which experiments and innovations take place at the farm level, and to make this innovative potential visible that could be relevant for such political initiatives. To be able to draw conclusions on farmers' innovative potential, we investigate whether organic farmers in Austria experiment, the topics, motives, methods and outcomes of farmers' experiments, and the factors related to the propensity to experiment. By doing so, our research aims at filling the knowledge gap on farmers' autonomous experiments in a 'non-development' context. We then discuss the significance of these experiments for adaptive farm management and for policy initiatives such as EIP-AGRI proposing possibilities to support farmers' experiments.

\section{Methods}

Research on farmers' experiments so far mainly used case studies of well-known experimenters. To be able to investigate the topic among 'average' organic farmers, we set up a structured questionnaire and applied it to a random sample of $10 \%$ of organic farmers in four regions of Austria. The questionnaire confronted all interviewees with the same set and sequences of questions. The pre-defined answer categories in the questionnaire were based on results and preliminary analysis of 47 semi-structured interviews carried out previously (Kummer, 2011), and on results from literature research. Answer categories included one- to multiple-choice answers, open-ended questions, and ratings along Likert scales (Bernard, 2006). We conducted two pre-test interviews to check if the questionnaire was comprehensible, and implemented final adaptations regarding wording and sequence of questions. Altogether, 76 organic farmers were interviewed with the questionnaire (Table 1). 
Table 1. Characteristics of interviewees $(n=76)$

\begin{tabular}{llccccc}
\hline Characteristics & Definition & \% & Arith. mean Median & Max & Min \\
\hline Sex & Male & $71 \%$ & & & & \\
& Female & $29 \%$ & & & & \\
Age (years) & & & 45.3 & 46 & 70 & 23 \\
Farm environment & Farm in mountainous region & $50 \%$ & & & & \\
& Farm in (predominantly) flat region & $50 \%$ & & & & \\
Farm operation type & Regular (full-time) & $46 \%$ & & & & \\
& Sideline (part-time) & $54 \%$ & & & & \\
Farm size (hectare) & & & 41.1 & 28 & 230 & 2 \\
Farming experience & Farmer since (years) & & 20.5 & 20 & 46 & 2 \\
& Organic since (years) & & 13.2 & 13 & 27 & 2 \\
\hline
\end{tabular}

We generated the random sample based on a complete list of all Austrian organic farmers that was provided by the Austrian Ministry of Agriculture (Bundesministerium für Land- und Forstwirtschaft, Umwelt und Wasserwirtschaft) after signing a confidentiality statement. We selected four regions that represented different climatic and agricultural production zones in Austria (Table 2). Region $1(\mathrm{~N}=135 ; \mathrm{n}=13)$ is located in the south-east of Austria, a flat to hilly area dominated by crop production. Region $2(\mathrm{~N}=146 ; n=13)$ comprises an alpine region in the north-west of Austria, characterised by grassland farming and animal husbandry (milking cows and suckler cows for meat production). Region $3(\mathrm{~N}=285 ; \mathrm{n}=25)$ is characterized by flat arable land of high productivity, comparably large farm sizes and intensive crop production, mainly without livestock. Region 4 $(\mathrm{N}=248 ; \mathrm{n}=25)$ is located in the north of Austria, characterized by continental climate and an emphasis on fodder crop production. The selected regions represent four of the eight agricultural production areas in Austria.

Table 2. Characteristics of the four study regions

\begin{tabular}{lllll}
\hline Characteristics & Region 1 & Region 2 & Region 3 & Region 4 \\
\hline Climatic zone & Temperate lowlands & Alpine region & Pannonian basin & Continental highland \\
Altitude above sea level & $200-400 \mathrm{~m}$ & $800-1500 \mathrm{~m}$ & $140-200 \mathrm{~m}$ & $500-600 \mathrm{~m}$ \\
Average annual temperature & $10.6^{\circ} \mathrm{C}$ & $7.2^{\circ} \mathrm{C}$ & $10.1{ }^{\circ} \mathrm{C}$ & $8.3^{\circ} \mathrm{C}$ \\
Annual precipitation & $830 \mathrm{~mm}$ & $1370 \mathrm{~mm}$ & $540 \mathrm{~mm}$ & $780 \mathrm{~mm}$ \\
Proportion of organic farms & $9 \%$ & $17 \%$ & $11 \%$ & $24 \%$ \\
Average farm size & $18 \mathrm{ha}$ & $7 \mathrm{ha}$ & $49 \mathrm{ha}$ & $34 \mathrm{ha}$ \\
Main agricultural activities & Cropping, fruits, & Grassland, & Cropping, & Fodder crops, \\
& wine and vegetables & milk, beef & vegetables, sugar & forestry \\
& & & beet & \\
\hline
\end{tabular}

Data sources:

Data on average annual temperature and annual precipitation for the years 2009-2014 provided by Zentralanstalt für Meteorologie und Geodynamik [ZAMG] (http://www.zamg.ac.at).

Data on proportion of organic farms and average farm size for the year 2012 provided by Agrarmarkt Austria [AMA].

All data have been processed and compiled by the first author.

We are aware that the sample is not representative for all organic farmers in Austria, but still we can draw conclusions from this sample to the overall situation of organic farmers' experiments in the country, as we selected four contrasting regions representing major differences within agricultural production in Austria, and applied a random sample of $10 \%$ of the total organic farmers in each region. The relatively small sample size is mainly due to our decision to conduct personal interviews on the respondents' farms, and not to send out the questionnaire per mail or e-mail. We consciously decided to apply the questionnaire in 'face-to-face' settings, as we had the experience from the semi-structured interviews conducted previously that the topic of farmers' experimentation is not self-explanatory and needs a qualitative explanation and the possibility to ask questions to get into the topic and find a common language and wording.

In each interview setting one researcher and the farmer were sitting together on a table with the questionnaire positioned in front of them in a way that both persons were able to read the text. The researcher read the questions out loud in the sequence of the questionnaire, and the farmer read the answer categories and decided which answers applied. In this face-to-face setting, interviewees were able to ask questions or make qualitative comments and explanations to the questionnaire. Each interview started with a short introduction in the research 
topic by reading the following definition to the interviewee: 'When we use the terms trying or experimenting we refer to how YOU test and monitor if and how something works, and if it is suitable for your farm. We explicitly do not refer to scientific experiments, but to practical experiments of organic farmers taking place at their farms.' After this introduction, farmers were asked to freely list experiments they had conducted on their farms. To learn about the individual experimentation process in a detailed way, one of the mentioned topics was then selected together with the interviewee, and systematic questions about topics, motives, methods and outcomes of these experiments followed. At the end of each interview, socioeconomic data about the farmer and the respective farm was inquired.

For data analysis, we applied descriptive and statistical analysis (frequencies and Spearman correlations), using the software SPSS and Microsoft Excel. Regarding significance levels for correlations, we defined $p<0.01$ as highly significant, and $\mathrm{p}<0.05$ as significant. In the results section, we present quantitative data from 76 structured questionnaire interviews. As eight of the interviewees stated not to experiment ('non-experimenters'), most results are based on answers from 68 interviewees, if not indicated differently.

\section{Results}

From all 76 interviewed farmers, $89.5 \%$ reported at least one activity in the past where they had experimented on their farms, and eight farmers (10.5\%) stated that they had never carried out any experiment. Regarding the frequency of experimenting, $18.4 \%$ stated that they 'very often' experimented (i.e. frequently during each season or year), $34.2 \%$ stated to experiment 'sometimes' (i.e. at least once every season or year), and $36.9 \%$ stated to experiment 'rarely' (i.e. not regularly and not every year). Farmers were asked to freely list experiments they had carried out. Between one and ten experiments were mentioned, with an arithmetic mean of 3.1 experiments per farmer. In total, the interviewees mentioned 239 individual experiments, and 68 experiments were discussed in detail.

\subsection{Topics of Farmers' Experiments}

Farmers were asked for all kinds of experiments they conducted on their farm in order to assess the full range of experimental activities of organic farmers. The 239 experiments mentioned by interviewees were clustered into 13 topics (Table 3 ).

Table 3. Frequency of topics for farmers' experiments according to thematic clusters (239 experiments mentioned by interviewees, $\mathrm{n}=68$ )

\begin{tabular}{lc}
\hline Topics & $\mathbf{\%}$ \\
\hline Plant production & $\mathbf{5 1 . 0 \%}$ \\
Cropping, plant production & $23.8 \%$ \\
Tillage, soil management & $13.8 \%$ \\
Weed and pest management & $6.3 \%$ \\
Fertilization & $5.4 \%$ \\
Vegetable, fruit and wine growing & $1.7 \%$ \\
Animal husbandry & $\mathbf{1 6 . 7 \%}$ \\
Processing and commercialization & $\mathbf{1 5 . 5 \%}$ \\
Processing & $8.8 \%$ \\
Commercialization & $6.7 \%$ \\
Other areas & $\mathbf{1 6 . 8 \%}$ \\
Alternative remedies and supplements & $6.3 \%$ \\
Tools, machinery, construction & $6.3 \%$ \\
Labor management / reduction & $1.3 \%$ \\
Social issues & $1.3 \%$ \\
Others & $1.6 \%$ \\
\hline
\end{tabular}

Of all experiments, $51 \%$ were conducted in the context of plant production, cropping and tillage, and included testing of

- new crops and varieties;

- different tillage tools and systems, including systems such as ploughless tillage, reduced tillage and direct sowing;

- different alternatives within plant production, e.g. intercropping and undersowing; 
- possibilities for optimizing the crop rotation;

- different methods of weed control, e.g. different tools and machines for tillage, methods and time schedules for mechanical weed control, or introducing new crops into the crop rotation to suppress weeds;

- different fertilizers, e.g. commercial organic fertilizers, farm manure, compost or mulching.

Experiments in the area of animal husbandry (17\%) included testing of

- new breeds and species on the farm;

- different feedstuffs and optimization of feed composition;

- different ways to handle animals, e.g. rearing animals and young animals (assistance before, during and after birth, handling and feeding of suckling animals);

- new forms of housing and pasturing;

- converting to alternative husbandry systems, e.g. from dairy farming to suckler cow systems.

Experiments regarding processing and commercialization (16\%) included testing of

- recipes, new ingredients, development of new products, establishment of product ranges, and improvements in processing procedures;

- different marketing systems, e.g. implementation of direct selling (farm shops, self-harvest systems, web shops, catering).

A range of further experimentation activities (17\%) were found in the interviews and included

- technical experiments, i.e. testing or modifying and adapting tools and machinery on the farm, or experiments in the context of farm constructions;

- testing of different alternative remedies, preparations and supplements to improve plant or animal health, or to improve compost, manure and soil quality, e.g. testing of effective microorganisms, homeopathy, biodynamic preparations, and other alternative remedies, or testing the lunar influence and farming according to the moon's cycle;

- experiments to reduce farm labor;

- implementation of social activities on the farm, e.g. offering educational activities or holidays on the farm.

\subsection{Motives and Information Sources for Farmers' Experiments}

The majority of the interviewees considered personal reasons (i.e. intrinsic motives like interest or curiosity) as an important motive to start an experiment. Other important motives were confronting challenges and problem solving (i.e. extrinsic motives) (Figure 1).

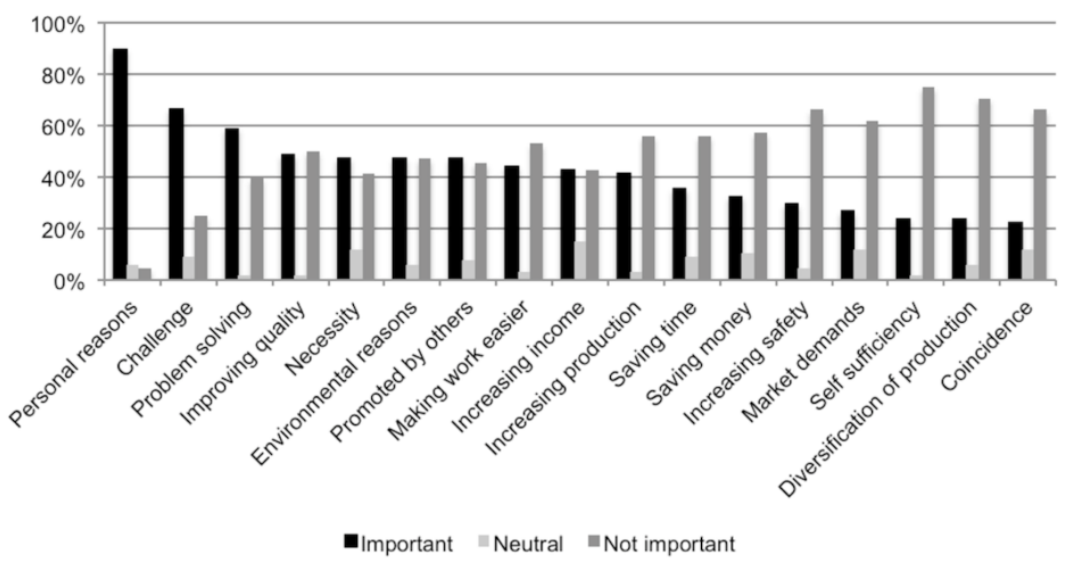

Figure 1. Importance of motives for farmers' experiments $(n=68)$

These results suggest that by experimenting farmers not only respond to external incentives or problems, but to the same extent have proactive motives for experimenting, developing the farm into a desired direction according to personal values and aims. Both types of motives are important features to enhance the adaptability 
of farms.

Eighty-four percent of the experimenting farmers had searched for information before or during their experiments. Literature was rated as most important information source, and also other farmers and advisors were considered important. Scientists were rated as least important information sources, indicating the well-known gap between farmers' and scientists' knowledge systems (Figure 2).

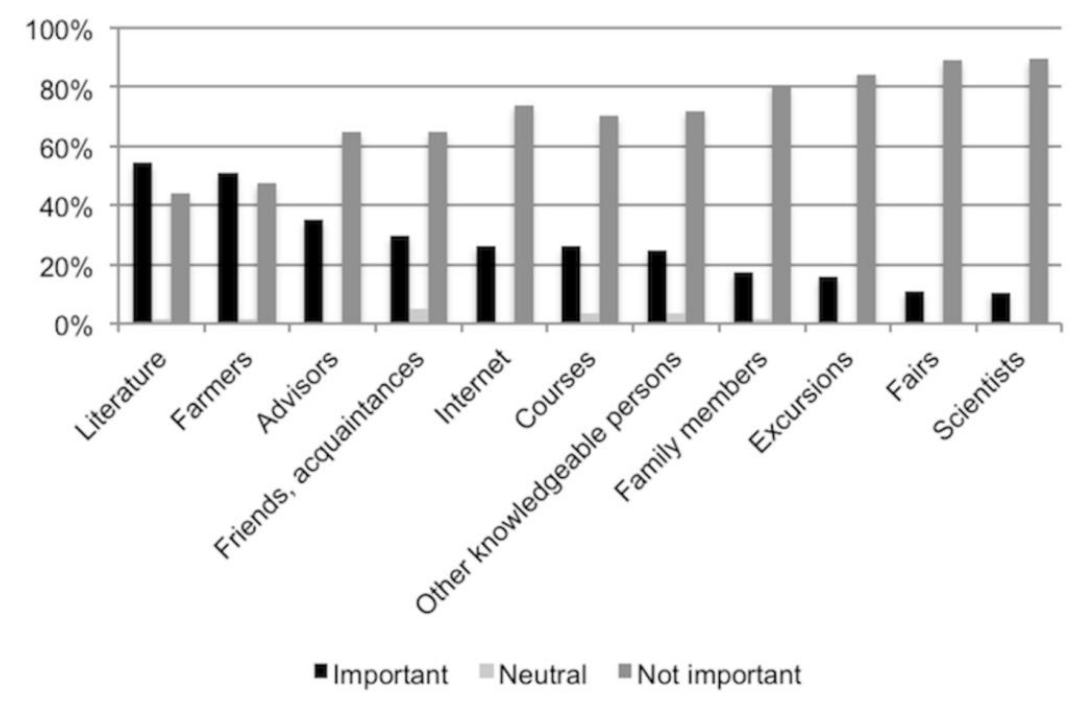

Figure 2. Importance of information sources for farmers' experiments $(n=68)$

\subsection{Methods and Outcomes of Farmers' Experiments}

Two thirds of the interviewees had an explicit mental or written plan before starting an experiment (Table 4). The majority (63\%) of the experimenting farmers stated that they set up their experiments first on a small scale and enlarged them if the outcome of the experiment was satisfactory. By doing so, farmers were able to first try a new method or practice with little risk. Thirty-seven per cent started the experiment on a large scale, either because they were convinced the new method would work satisfactorily, or because it was difficult or impossible to run a small-scale test. The impracticability of a small-scale test was often cited in the case of experiments involving technical constructions such as buildings or machinery that were implemented at once for the entire production unit. Setting up a test version in these cases would have been more costly than the construction of the entire production unit.

The majority (94\%) of experimenting farmers monitored the progress of their experiments, mainly through observation, but also by comparisons. A small share of interviewees employed some kind of measurements, e.g. yield quantity, counting (e.g. of plants affected by a certain disease), or economic measurements (e.g. price calculations for different processed products for marketing). To evaluate the success or failure of an experiment, most interviewees compared their experiments with experiences from former experiments (historical comparison), and with units or experiences of other farmers. Comparisons with other units or practices on their own farm (including side-by-side comparisons), with results described in literature, and with information from advisors or other experts in the subject were employed less frequently (Table 4).

Of the experimenting farmers, $57 \%$ stated that they had documented their experiments by taking individual notes, but also obligatory records that farmers had to provide to comply with requirements of the regulation on organic farming and the agricultural subsidy system were seen as a possibility to document experiments. Less frequent documentation strategies involved taking photos, taking samples, or making a video (Table 4). 
Table 4. Frequency of different methods used in farmers' experiments ( $n=68$; multiple answers possible)

\begin{tabular}{ll}
\hline Methods & \% \\
\hline Planning & $69.1 \%$ \\
Mental plan & $55.9 \%$ \\
Written plan & $13.2 \%$ \\
No explicit plan & $30.9 \%$ \\
\hline Monitoring & $94.1 \%$ \\
Observation & $88.2 \%$ \\
Comparisons & $82.4 \%$ \\
Measurements & $13.2 \%$ \\
No monitoring & $5.9 \%$ \\
\hline Comparisons & $82.4 \%$ \\
With own experiences & $78.6 \%$ \\
With other farmers & $64.3 \%$ \\
With other unit on the farm & $26.8 \%$ \\
With results from literature & $23.2 \%$ \\
With information from advisors & $10.7 \%$ \\
No comparison & $17.6 \%$ \\
\hline Documentation & $57.4 \%$ \\
Taking notes & $33.8 \%$ \\
Obligatory records & $33.8 \%$ \\
Photographs & $16.2 \%$ \\
Taking sample & $4.4 \%$ \\
Video & $2.9 \%$ \\
No documentation & $42.6 \%$ \\
\hline
\end{tabular}

Obtaining more knowledge was rated as most important outcome of experiments. The pre-defined answer categories that applied least for the interviewed farmers were: reduction of labor, increasing income, and increasing production (Figure 3). Regarding labor reduction, several farmers stated that the outcome of the specific experiment (e.g. new product, new or additional marketing channel) resulted in even more work, or that the overall outcome (e.g. new working method) did not increase the income directly, or may even have caused additional costs.

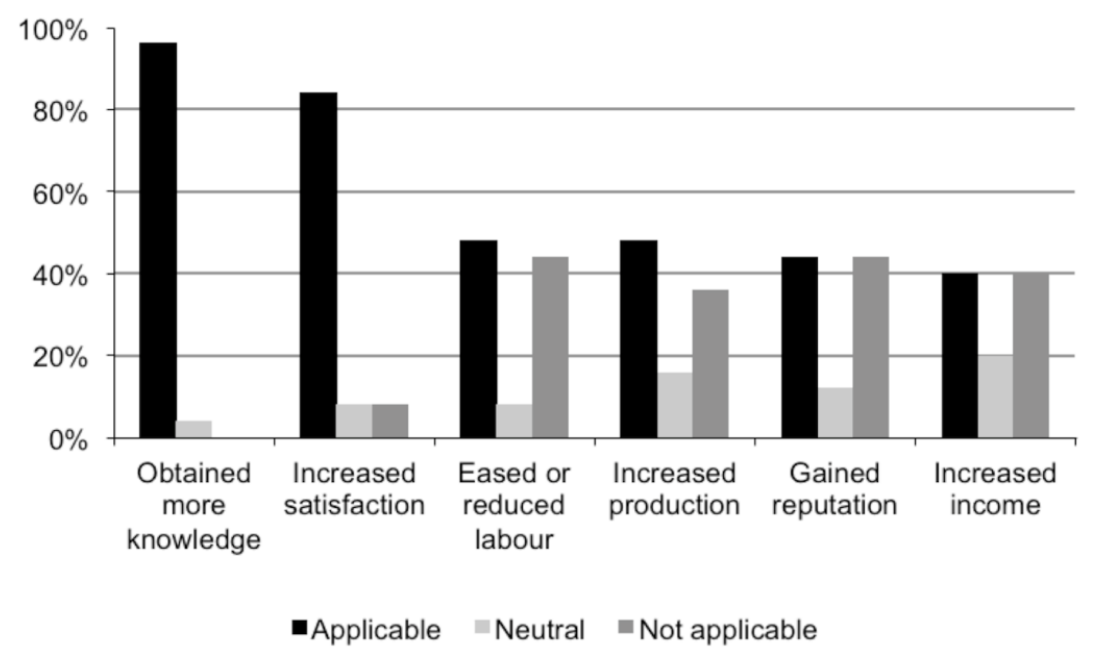

Figure 3. Frequency of different kinds of outcomes of farmers' experiments ( $n=68,1$ missing case, $67=100 \%)$

About half of the experimenting farmers (47\%) reported that other persons had used the results of their experiments, most often other farmers $(90 \%)$ and friends $(31 \%)$, but rarely advisors or scientists $(6 \%$ in each case), indicating that the dissemination of experiments' outcomes was mainly limited to the personal network of 
the farmers and received little attention by the official research and advisory system.

\subsection{Factors related to the frequency of experimentation}

Some methodological differences in the experimentation process were significantly related to the frequency of experimentation: Farmers with a high frequency of experimentation showed a higher propensity to set up written or mental plans before starting an experiment, and they more often documented and repeated their experiments (Table 5).

Table 5. Correlation between frequency of experimentation and methods used in farmers' experiments $(\mathrm{n}=68 ; \%$ within frequency of experimentation categories)

\begin{tabular}{lccccc}
\hline & \multicolumn{2}{c}{$\begin{array}{c}\text { Frequency of experimentation } \\
\text { Very often }\end{array}$} & Sometimes & Rarely & Spearman correlation \\
\hline Methods & $\boldsymbol{\%}$ & $\mathbf{\%}$ & $\mathbf{\%}$ & $\mathbf{r}$ & $\mathbf{p}$ \\
\hline Written plan & $28.6 \%$ & $15.4 \%$ & $3.6 \%$ & $0.321^{* *}$ & 0.008 \\
Mental plan & $50.0 \%$ & $65.4 \%$ & $50.0 \%$ & & \\
No plan & $21.4 \%$ & $19.2 \%$ & $46.4 \%$ & & \\
Documentation & $92.9 \%$ & $57.7 \%$ & $39.3 \%$ & $0.384^{* *}$ & 0.001 \\
No documentation & $7.1 \%$ & $42.3 \%$ & $60.7 \%$ & & \\
Repetition & $85.7 \%$ & $53.8 \%$ & $42.9 \%$ & $0.259^{*}$ & 0.015 \\
No repetition & $14.3 \%$ & $46.2 \%$ & $57.1 \%$ & & \\
\hline
\end{tabular}

Socio-economic factors that were not found to have an influence on the propensity to experiment were mode of farm operation (full-time or part-time) $(r=0.177 ; p=0.125)$, age $(r=0.136 ; p=0.240)$, sex $(r=0.072 ; p=0.534)$, level of education $(\mathrm{r}=0.003 ; \mathrm{p}=0.982)$, or years of farming experience $(\mathrm{r}=0.032 ; \mathrm{p}=0.783)$. On the other hand, farmers who owned bigger farms reported a higher experimentation frequency, although the correlation between farm size and frequency of experimentation is slightly below the significance level $(\mathrm{r}=0.215 ; \mathrm{p}=0.062)$.

Significant correlations were found between the frequency of experimentation and personal habits and characteristics of the interviewees, such as travel habits: Farmers who stated that they often experimented showed a higher travel activity outside Austria $\left(r=0.253^{*}, \mathrm{p}=0.028\right)$ and outside Europe $\left(\mathrm{r}=0.410^{* *}, \mathrm{p}=0.000\right)$. To gain an insight how personal attitudes were related to the propensity to experiment, we provided farmers with pre-defined statements. Farmers who reported a high frequency of experimentation agreed significantly more with the statement that they 'like to do things differently than others do', and that 'change and challenges make my life interesting'. In contrast, farmers who reported a low experimentation frequency agreed significantly more often with the statement that they 'like it when things are stable', and that they 'only change things when necessary'. Interestingly, farmers with a low experimentation frequency also agreed significantly more often to the statements 'I am well structured and organized' and 'I pass on my ideas and experiences' than frequent experimenters, indicating that some frequent experimenters did not want to communicate their findings, and that experimentation tends to involve a certain degree of chaos (Table 6). These results suggest that farmers reporting a high frequency of experimentation consciously define themselves as experimenters and innovators, whereas less frequent experimenters adhere more to values of tradition and stability, indicating that personality may have a significant influence on the propensity to experiment. 
Table 6. Correlation between frequency of experimentation and farmers' attitudes to experimenting ( $\mathrm{n}=76 ; \%$ within frequency of experimentation categories for each statement)

\begin{tabular}{|c|c|c|c|c|c|c|c|}
\hline & & \multicolumn{4}{|c|}{ Frequency of experimentation } & \multicolumn{2}{|c|}{$\begin{array}{l}\text { Spearman } \\
\text { correlation }\end{array}$} \\
\hline \multicolumn{2}{|l|}{$\begin{array}{l}\text { Statement about farmers' } \\
\text { attitude to experimenting }\end{array}$} & $\begin{array}{c}\text { Very } \\
\text { often }\end{array}$ & $\begin{array}{c}\text { Some- } \\
\text { times }\end{array}$ & Rarely & Never & $\mathbf{r}$ & $\mathbf{p}$ \\
\hline \multirow{3}{*}{$\begin{array}{l}\text { like to do tnings } \\
\text { differently than others do. }\end{array}$} & Agree & $92.9 \%$ & $80.8 \%$ & $50.0 \%$ & $37.5 \%$ & $0.384 * *$ & 0.001 \\
\hline & Neutral & $0.0 \%$ & $7.7 \%$ & $0.0 \%$ & $0.0 \%$ & & \\
\hline & Don't agree & $7.1 \%$ & $11.5 \%$ & $50.0 \%$ & $62.5 \%$ & & \\
\hline Change and challenges & Agree & $92.9 \%$ & $80.8 \%$ & $50.0 \%$ & $62.5 \%$ & $0.353 * *$ & 0.002 \\
\hline \multirow{2}{*}{ make my life interesting. } & Neutral & $7.1 \%$ & $15.4 \%$ & $21.4 \%$ & $12.5 \%$ & & \\
\hline & Don't agree & $0.0 \%$ & $3.8 \%$ & $28.6 \%$ & $25.0 \%$ & & \\
\hline \multirow{3}{*}{$\begin{array}{l}\text { I only try or change things } \\
\text { when it is necessary. }\end{array}$} & Agree & $14.3 \%$ & $42.3 \%$ & $42.9 \%$ & $62.5 \%$ & $-0.288^{*}$ & 0.012 \\
\hline & Neutral & $0.0 \%$ & $11.5 \%$ & $14.3 \%$ & $12.5 \%$ & & \\
\hline & Don't agree & $85.7 \%$ & $46.2 \%$ & $42.9 \%$ & $25.0 \%$ & & \\
\hline \multirow{3}{*}{$\begin{array}{l}\text { I like it when things are } \\
\text { stable. }\end{array}$} & Agree & $14.3 \%$ & $57.7 \%$ & $82.1 \%$ & $87.5 \%$ & $-0.478 * *$ & 0.000 \\
\hline & Neutral & $28.6 \%$ & $23.1 \%$ & $7.1 \%$ & $0.0 \%$ & & \\
\hline & Don't agree & $57.1 \%$ & $19.2 \%$ & $10.7 \%$ & $12.5 \%$ & & \\
\hline \multirow{3}{*}{$\begin{array}{l}\text { I pass on my ideas and } \\
\text { experiences to others. }\end{array}$} & Agree & $71.4 \%$ & $80.8 \%$ & $92.9 \%$ & $100.0 \%$ & $-0.267 *$ & 0.020 \\
\hline & Neutral & $21.4 \%$ & $15.4 \%$ & $7.1 \%$ & $0.0 \%$ & & \\
\hline & Don't agree & $7.1 \%$ & $3.8 \%$ & $0.0 \%$ & $0.0 \%$ & & \\
\hline \multirow{3}{*}{$\begin{array}{l}\text { I have my things well } \\
\text { structured and organized. }\end{array}$} & Agree & $35.7 \%$ & $57.7 \%$ & $60.7 \%$ & $75.0 \%$ & $-0.227^{*}$ & 0.049 \\
\hline & Neutral & $21.4 \%$ & $34.6 \%$ & $21.4 \%$ & $25.0 \%$ & & \\
\hline & Don't agree & $42.9 \%$ & $7.7 \%$ & $17.9 \%$ & $0.0 \%$ & & \\
\hline
\end{tabular}

\section{Discussion}

The majority of the interviewed farmers reported that they had carried out activities of experimental character on their farms, and most of them listed several topics of experimentation. The capacity of farmers to experiment is widely accepted within the scientific community (e.g. Bentley, 2006; Hoffmann et al., 2007; Johnson, 1972; Maat, 2011; Reij \& Waters-Bayer, 2001b; Sumberg \& Okali, 1997; Tambo \& Wünscher, 2014; Wortmann et al., 2005). Literature in the context of participatory research mainly focuses on cases of active experimenters (Haverkort et al., 1991; Reij \& Waters-Bayer, 2001b), 'research-minded farmers' (Biggs, 1990) and 'farmer innovators' (Critchley, 2000; Tambo \& Wünscher, 2014), and thus little is known about less active experimenters, or the relative proportions of active and less active experimenters. In this random sample, $18.5 \%$ of the interviewees declared themselves as very active experimenters, $71 \%$ reported to experiment sometimes or rarely ('less active experimenters'), and $10.5 \%$ of the interviewees reported not to experiment at all.

Frequent experimenters in this study significantly more often had an explicit plan for their experiments, and more often documented and repeated their experiments. This may be due to the fact that these farmers are more aware of their experiments and define themselves as experimenters, in contrast to the majority of farmers that presumably do not see experiments as particular research processes but rather as a normal part of every day farming activities (Saad, 2002). Characteristics such as replication and documentation are seen as crucial for evaluating the success of experiments and for fine-tuning production systems (Wortmann et al., 2005).

Socio-economic factors that influence the propensity for farmers' experiments mentioned in literature are age, sex, education level, farming occupation (full-time or part-time), socio-economic status, and political, social or ecological constraints (Critchley \& Mutunga, 2003; Saad, 2002; Sumberg \& Okali, 1997). In this study, no socio-economic factors were found to have a significant influence on the frequency of experimentation. This is in line with Sumberg and Okali (1997), who found that there were no strong relationships between the socio-economic characteristics they assessed and either the propensity to experiment or the characteristics of the experiments. However, some similarities can be found among experimenting farmers described in the literature, and these refer mainly to personal characteristics of the farmers. For example, many farmer experimenters have travelled and experienced other areas (Critchley \& Mutunga, 2003) and many are devoted to full-time farming and are flexible enough to experiment (Reij \& Waters-Bayer, 2001a). In this study, frequent experimenters reported higher travelling activities to distant places and reported a significantly more positive attitude towards experimenting. 
Altogether our results suggest that most farmers do experiment, but only a smaller group of farmers define themselves as active experimenters. The higher frequency of experimentation is mainly related to personal characteristics and positive attitude towards experimenting. Stimulating a positive attitude of farmers towards experimenting may therefore have a significant influence on the propensity to experiment.

\subsection{Topics, Motives and Information Sources for Farmers' Experiments}

Most of the experiments discussed in the interviews concerned agronomic topics, but also non-agronomic topics such as processing and commercialization, alternative remedies, labor management, or social issues. Literature mainly concentrates on experiments in the area of crop production and related activities such as fertilization or tillage (Leitgeb et al., 2014; Sumberg \& Okali, 1997; van Veldhuizen et al., 1997). Sumberg and Okali (1997) catalogued 155 examples of farmers' experiments in three African countries and found that only $5 \%$ of the experiments were about non-agronomic topics such as labor management and marketing. This points to a certain 'blind spot' within agricultural research, and so integrating farmers' experiments better into the respective agricultural innovation systems could help to broaden the perception of which topics or problems have relevance and priority for farmers, and how they could be adequately addressed.

The frequency of non-agronomic topics in comparison to research findings of studies carried out in a development context may also be due to the fact that farming in industrialized countries is partly moving from the production of agricultural raw products to more multifunctional farm activities (Björklund \& Milestad, 2006; Hubert, Ison, \& Röling, 2000) and rural development activities (Darnhofer, 2005), a development that is also driven by the Common Agricultural Policy (CAP) of the EU (Morgan, Marsden, Miele, \& Morley, 2010). Another factor that influences agricultural activities is decreasing prices due to market liberalization (Hubert et al., 2000). Decreasing agricultural income motivates farmers to experiment with alternative marketing strategies such as direct marketing, or with the production of alternative goods and services such as composting of organic residues for the community, or social services such as education or leisure time activities (parties, catering, holidays) on farm. Decreasing income in agriculture and changed social conditions, such as off-farm work of farmers or the attempt to separate farm work from family life, also causes farmers to search for time saving measures (Cournut \& Dedieu, 2006).

Both reactive and proactive motives drive farmers to experiment and by doing so enhance the adaptability of their farms (Darnhofer et al., 2010). In the context of rapid and constant changes affecting farming activities, it is particularly important to adequately and actively respond to change, rather than reacting to the adverse impact of change. This requires the ongoing development of a range of alternative activities and resource use patterns that can be implemented quickly if needed (Milestad et al., 2012), and these alternatives can be developed and tested through experimenting.

As most important information sources to carry out experiments, the interviewed farmers ranked literature, farmer colleagues and advisors. Scientists were ranked as least important information sources, indicating that the interviewed farmers in Austria are not well connected to academic agricultural research, or that scientists fail to provide research results in a way that farmers want to use it. Results of academic research such as academic papers are generally complex and theoretical, and therefore inappropriate information sources for practical farming problems (Sewell et al., 2014). Or putting it more drastically: many farmers consider 'expert knowledge' as being of limited practical value (Lyon, Bell, Gratton, \& Jackson, 2011; Stuiver et al., 2004), and prefer insider information coming from other farmers (Hoffmann et al., 2007; Schneider, Fry, Ledermann, \& Rist, 2009). The situation can be different in other contexts, e.g. in Cuba, where efforts to enhance information exchange between scientists, farmers and extensionists were successful, and farmers' experiments are institutionalized and well integrated into the agricultural innovation system (Leitgeb et al., 2011). Similar approaches also exist in the European context, for example 'farmer-to-farmer'-approach (Schneider et al., 2009) or farmer stable schools (Vaarst et al., 2007).

\subsection{Methods and Outcomes of Farmers' Experiments}

When analyzing farmers' individual experiments, we found similar characteristics like comparable studies: most experiments involved planning (Sumberg \& Okali, 1997), small-scale setup (Saad, 2002; Sturdy et al., 2008), monitoring strategies such as frequent observation (Stolzenbach, 1999) and comparisons (both historical and direct comparisons) (Sumberg \& Okali, 1997), and resulted in incremental improvements and minor modifications of established practices (Sumberg et al., 2003). In this sense, farmers' experiments share communalities with experiments of formal agronomic research (Maat, 2011; Sumberg et al., 2003). Beyond these similarities, the particularity and significance of farmers' experiments becomes evident when evaluating less the products but rather the process involved (Saad, 2002). These processes of experimentation are characterized by 
flexibility and adaptive performance, and are significantly different from the standardized experimental design generally employed in academic research (Vogl, Kummer, Leitgeb, Schunko, \& Aigner, 2015). Spontaneous variation during experimentation is considered a valid source of information itself, and it can be the essence of success for an experiment (Stolzenbach, 1999).

Farmers have their own methods for carrying out and evaluating experiments (Bentley, 2006), and these methods are adapted to the needs and reality of the respective farm. Strengthening farmers' experiments is sometimes interpreted as the need to formalize them by including e.g. replications, standardizations and quantifications (Wilbois et al., 2004), but there is little if any evidence that training farmers in more formal research methods would make their experiments more effective (Sumberg et al., 2003). Additionally, such a formalization is likely to increase the cost and risk of experimentation (Sumberg \& Okali, 1997), and requires additional time (Wortmann et al., 2005). Some authors even suspect that introducing scientific methods may sidetrack farmers into pseudo-scientific trials that do not take advantage of their own knowledge, especially when formal research is seen as more valid and relevant (Saad, 2002). Academic and farmers' research may have different approaches, but both are relevant for the further development of sustainable farming systems. Exchange between these two areas of research could be beneficial for both areas (Hoffmann et al., 2007). Farmers could use formal research results as an inspiration and source of information in their experiments, and some of the farmers in our study were found to do exactly this. In the same vein, outcomes of farmers' experiments could be spread to other farmers, incorporated into advisory programs, and act as an incentive for researchers.

Interviewees stressed the importance of learning and development of knowledge through experimenting. By monitoring the process and outcomes of experiments, farmers widen the repertoire of options to deal with and confront change, and gain context specific knowledge to actively adapt their farm management. In this sense, farmers' experiments are powerful tools to build up farmers' knowledge and to strengthen the adaptability and resilience of farms (Darnhofer et al., 2010; Kummer, Milestad, Leitgeb, \& Vogl, 2012), but this is not necessarily the case. In some cases, an experiment may put the farm at risk (e.g. experimenting on too large scale), may make the farm more dependent on external resources (e.g. experiments that increase off-farm purchases), or may reduce diversity (e.g. experiments that aim to maximize output of one product at the expense of others). When supporting or advising farmers, it is therefore important to raise awareness for possible risks of experimentation. A resilience framework can help to distinguish between risky experimentation and experiments that support sustainable development of the farm (Kummer et al., 2012).

\subsection{Integrating Farmers' Experiments into AIS}

Farmers' experiments can be a driving force for agricultural development when integrated into the agricultural innovation system, as it is the case in Cuba (Leitgeb et al., 2011). There is potential to make more active use of farmers' experiments and innovations by raising awareness for the topic within the farming community, the respective political and institutional landscape, and the agricultural research and advisory services. But raising awareness will probably not be enough, as e.g. even extensionists working intensively with farmers in participatory research projects are often not aware of the experimental capacity of farmers (Bentley et al., 2010). It will be crucial to find appropriate ways of participatory research and joint learning between the actors within the AIS, and lately a considerable number of promising concepts evolved, such as adaptive co-management (Armitage, Marschke, \& Plummer, 2008), networks of practice (Oreszczyn, Lane, \& Carr, 2010), or learning and innovation networks (Brunori et al., 2013; Moschitz, Roep, Brunori, \& Tisenkopfs, 2015). Concrete examples how to make more active use of farmers' experimental capacities include experiential learning groups of Danish dairy farmers that developed concrete solutions to improve the health of their herds based on mutual advice, group induced experiments and common evaluation of the results (Vaarst et al., 2007). In Switzerland, farmers' experiments with soil protection measures were used in films to inspire other farmers, but finally the films were found to have a far-reaching impact on various actors and institutions involved in soil protection, induced social learning and helped to overcome traditional conflicts between the involved actors (Schneider et al., 2009).

A possibly promising pathway to integrate farmers' research better into the agricultural innovation system is formulated in the European Innovation Partnership (EIP) of the European Commission (EC) on 'Agricultural Productivity and Sustainability'. The EIP stresses the importance of innovation and knowledge exchange in the agrarian sector to meet societal challenges of food production. 'Increased and sustainable agricultural output will be achievable only with major research and innovation efforts at all levels. Repeatedly, researchers and stakeholders have highlighted the gap between the provision of research results and the application of innovative approaches to farming practice. New approaches take too long to arrive on the ground, and the needs of practical farming are not communicated sufficiently to the scientific community. Thus, important innovations are not implemented on the necessary scale, (...).' (European Commission [EC], 2012, p.3). Although the EC paper 
stresses the necessity to 'help translating research results into actual innovation' (EC, 2012, p.5), which could be understood as yet another example of the overcome 'transfer of technology' approach, the EC paper also emphasizes the need for systemic feedback from practice to science, for enhancing knowledge exchange, and for joint efforts to invest in sustainable innovation. Furthermore it is suggested that the EIP aims at enhancing communication and cooperation between science and practice. It will help sharing experience, including failures, lessons learned, and good practice.'(EC, 2012, p.7). Within the context of agricultural innovation development, a shift from linear technology-oriented approaches to systems-oriented approaches to innovation has taken place over the last decades (Klerkx et al., 2012; Schut et al., 2014), and the current EIP seems to acknowledge this development (Moeskops, Blake, Tort, \& Torremocha, 2014). The results of our research suggest that a certain group of farmers interested and actively engaged in experiments and the development of local innovations have the relevant knowledge and skills to contribute to the pursued European partnership.

To take advantage of the potential of farmers' experiments, it is important to develop conditions that support farmers in their experimentation activities (Chikozho, 2005; Johnson, 1972; Quiroz, 1999). National regulations, subsidies and support payments could be used to give farmers room for creativity within the regulatory frameworks for farming. Another possibility would be to engage farmers more actively in the advisory system and in technology development (Maat, 2011; Sumberg et al., 2003), and make active use of the outcomes of farmers' experiments for the development of local agricultural systems (Leitgeb et al., 2011). Studies that investigated the introduction of new farming practices in Europe, USA or Australia conclude that especially advisors are sometimes not open to new developments and even prevent farmers from engaging in those practices, and frequently the farmers themselves are drivers to establish novel farming practices and innovations (Ingram, 2010; McKenzie, 2013). With all the enthusiasm for participatory and social learning approaches, we also have to consider their disadvantages, as they require considerable resources such as time and budget. It will therefore be crucial to respect these opportunity costs (Hoffmann et al., 2007), e.g. by establishing effective compensation programs and political incentives (Armitage et al., 2008), or making sure that the benefits exceed the costs of participation (Home \& Rump, 2015).

\section{Conclusion}

Based on our findings, we conclude that farmers' experimentation is significant on two levels or scales. Firstly, experiments have concrete significance on the individual farm level, as they involve learning processes, and the knowledge developed through experimenting helps to enhance the adaptive capacity of farms. Outcomes of experiments can provide possible strategies to adapt to changing conditions, and to actively take up emerging opportunities. Secondly, we conclude that the outcomes of experiments frequently have an outreach on the regional level and/or into the wider agricultural innovation system: some experiments result in local innovations that can be useful in the regional context or for similar conditions. Frequent experimenters developing these innovations have in-depth knowledge on the subject, and have monitored and tested their developments over time. They are possible advisors for other farmers and partners, e.g. for EIP-AGRI initiatives.

Both levels of experiments are important within the AIS, but on different scales and within different networks. To stimulate experiments on farm level, it will be helpful to make farmers more aware of their experimenting potential and encourage them to use it, e.g. by providing relevant information and offer possibilities of knowledge exchange. Presenting positive examples of farmers' experiments and stressing their significance may also have a positive influence on farmers' general attitude towards experimenting and motivate farmers to experiment. For the level of agricultural innovation systems, it could be supportive to encourage the dissemination of outcomes of farmers' experiments, to integrate interested farmers into participatory research or initiatives such as EIP-AGRI, and to support already existent learning and innovation networks. Investigating concrete possibilities and tools to integrate farmers' experiments into the agricultural knowledge and innovation system is the next logical step building on this basic research, so currently our suggestions are still on a general level. Research and policy initiatives that relate to the topic of farmers' experiments and innovations, such as the EIP-AGRI, provide a possible framework to further this research into a more applied direction.

Concerning the current European Innovation Partnership on Agriculture (EIP-AGRI), we can draw two conclusions: Firstly, EIP-AGRI states that research results do not reach the farmers, and at the same time the needs of practical farming do not reach the scientific community. Our results support this observation, as the interviewed farmers ranked scientists as least important information source for their experiments, and only in few cases were outcomes of farmers' experiments taken up by scientists and advisors. Secondly, EIP-AGRI claims the need to enhance communication and cooperation and share experiences between science and practice. We conclude that in order to tackle current challenges of farming and food production, it will be crucial to involve interested farmers as co-researchers into the development of innovative solutions. The concept of 
co-learning and co-production of knowledge within agricultural innovation systems could be a suitable framework to benefit from the specific skills and knowledge of the involved actors. Experimenting farmers have relevant experiences to share with other stakeholders in the agricultural system. When implemented in an appropriate way, the current European Innovation Partnership could be a base for making more active use of the innovative potential of farmers' experiments.

\section{Acknowledgements}

The authors thank the Austrian Science Foundation (FWF) for financing the project 'Organic Farmers' Experiments' (project P 19133). We are especially thankful to all the persons that took their valuable time for conducting interviews with us. We also thank persons and organizations that supported this work by providing data, information and inspiration: people from the organic farmers' association 'Bio Austria', the Chamber of Agriculture in the respective research regions, the organization 'Steirisches Vulkanland', the Ministry for Agriculture, and from FiBL Austria. Finally, we thank Andrea Moldaschl for her collaboration in data collection, Christoph Schunko for support in quantitative data analysis and for his valuable comments on earlier paper drafts, and our colleagues from the Working Group of Knowledge Systems and Innovations for the fruitful discussions on the subject of our research.

\section{Note}

This paper is partly based on the dissertation of the first author:

Kummer, S. (2011). Organic farmers' experiments in Austria. Learning processes and resilience building in farmers' own experimentation activities. (Doctoral thesis), University of Natural Resources and Life Sciences, Vienna. Retrieved from http://permalink.obvsg.at/bok/AC07810093

\section{References}

Armitage, D., Marschke, M., \& Plummer, R. (2008). Adaptive co-management and the paradox of learning. Global Environmental Change, 18, 86-98. http://dx.doi.org/10.1016/j.gloenvcha.2007.07.002

Bentley, J. W. (2006). Folk Experiments. Agriculture and Human Values, 23(4), 451-462. http://dx.doi.org/10.1007/s10460-006-9017-1

Bentley, J. W., van Mele, P., \& Acheampong, G. K. (2010). Experimental By Nature: Rice Farmers in Ghana. Human Organization, 69(2), 129-137. https://doi.org/10.17730/humo.69.2.r078vjvqx23675g1

Bernard, H. R. (2006). Research Methods in Anthropology. Qualitative and Quantitative Approaches (Fourth edition ed.). Oxford: Altamira Press.

Biggs, S. D. (1990). A multiple source of innovation model of agricultural research and technology promotion. World Development 18(11), 1481-1499. https://doi.org/10.1016/0305-750X(90)90038-Y

Björklund, J., \& Milestad, R. (2006). Multifunctional farms and rural development: A study of four Swedish rural areas. In H. Langeveld \& N. Röling (Eds.), Changing European farming systems for a better future (pp. 212-216). Wageningen: Wageningen Academic Publishers.

Brunori, G., Barjolle, D., Dockes, A.-C., Helmle, S., Ingram, J., Klerkx, L., ... Tisenkopfs, T. (2013). CAP Reform and Innovation: The Role of Learning and Innovation Networks. EuroChoices, 12(2), 27-33. https://doi.org/10.1111/1746-692X.12025

Chambers, R., Pacey, A., \& Thrupp, L. A. (Eds.). (1998). Farmer First: Farmer Innovation and Agricultural Research. London: Intermediate Technology Publications.

Chikozho, C. (2005). Policy and institutional dimensions of small-holder farmer innovations in the Thukela River Basin of South Africa and the Pangani River Basin of Tanzania: a comparative perspective. Physics and Chemistry of the Earth, 30, 913-924. http://dx.doi.org/10.1016/j.pce.2005.08.038

Cournut, S., \& Dedieu, B. (2006). How do dairy farmers face work problems? Some elements about the adaptation of the technical systems in Central France. In H. Langeveld \& N. Röling (Eds.), Changing European farming systems for a better future. New visions of rural areas (pp. 227-231). Wageningen: Wageningen Academic Publishers.

Critchley, W. R. S. (2000). Inquiry, Initiative and Inventiveness: Farmer Innovators in East Africa. Physics and Chemistry of the Earth, 25(3), 285-288. http://dx.doi.org/10.1016/S1464-1909(00)00016-2

Critchley, W. R. S., \& Mutunga, K. (2003). Local innovation in a global context: Documenting farmer initiatives in land husbandry through WOCAT. Land Degradation \& Development, 14(1), 143-162.

http://dx.doi.org/10.1002/ldr.537 
Darnhofer, I. (2005). Organic Farming and Rural Development: Some Evidence from Austria. Sociologia Ruralis, 45(4), 308-323. https://doi.org/10.1111/j.1467-9523.2005.00307.x

Darnhofer, I., Bellon, S., Dedieu, B., \& Milestad, R. (2010). Adaptiveness to enhance the sustainability of farming systems. A review. Agronomy for Sustainable Development, 30(3), 545-555. http://dx.doi.org/10.1051/agro/2009053

European Commission [EC] (2012). Communication from the Commission to the European Parliament and the Council on the European Innovation Partnership 'Agricultural Productivity and Sustainability'. COM(2012) 79 final, Brussels.

Gerber, A., Hoffmann, V., \& Kügler, M. (1996). Das Wissensystem im Ökologischen Landbau in Deutschland: Zur Entstehung und Weitergabe von Wissen im Diffusionsprozeß. Berichte über Landwirtschaft, 74, 591-627.

Haverkort, B., van der Kamp, J., \& Waters-Bayer, A. (Eds.). (1991). Joining farmers' experiments. Experiences in participatory technology development. London: Intermediate Technology Publications.

Hermans, F., Klerkx, L., \& Roep, D. (2015). Structural Conditions for Collaboration and Learning in Innovation Networks: Using an Innovation System Performance Lens to Analyse Agricultural Knowledge Systems. The Journal of Agricultural Education and Extension, 21(1), 35-54. http://dx.doi.org/10.1080/1389224x.2014.991113

Hoffmann, V., Probst, K., \& Christinck, A. (2007). Farmers and researchers: how can collaborative advantages be created in participatory research and technology development? Agriculture and Human Values, 24(3), 355-368. http://dx.doi.org/10.1007/s10460-007-9072-2

Home, R., \& Rump, N. (2015). Evaluation of a Multi-case Participatory Action Research Project: The Case of SOLINSA. Journal of Agricultural Education and Extension, 21(1), 73-89. http://dx.doi.org/10.1080/1389224X.2014.991112

Hubert, B., Ison, R. L., \& Röling, N. (2000). The 'Problematique' with Respect to Industrialised-Country Agricultures. In M. Cerf, D. Gibbon, B. Hubert, R. Ison, J. Jiggins, M. Paine, J. Proost \& N. Röling (Eds.), Cow Up A Tree. Knowing and Learning for Change in Agriculture. Case Studies from Industrialised Countries (pp. 13-29). Paris: INRA Editions.

Ingram, J. (2010). Technical and Social Dimensions of Farmer Learning: An Analysis of the Emergence of Reduced Tillage Systems in England. Journal of Sustainable Agriculture, 34(2), 183-201. http://dx.doi.org/10.1080/10440040903482589

Johnson, A. W. (1972). Individuality and experimentation in traditional agriculture. Human Ecology, 1, 149-159. https://doi.org/10.1007/BF01531352

Kandel, H. J., Porter, P. M., Carr, P. M., \& Zwinger, S. F. (2008). Producer participatory spring wheat variety evaluation for organic systems in Minnesota and North Dakota. Renewable Agriculture and Food Systems, 23(3), 228-234. http://dx.doi.org/10.1017/S1742170508002263

Klerkx, L., van Mierlo, B., \& Leeuwis, C. (2012). Evolution of systems approaches to agricultural innovation: concepts, analysis and intervention. In I. Darnhofer, D. Gibbon \& B. Dedieu (Eds.), Farming Systems Research into the 21st Century: The New Dynamic. Dordrecht: Springer.

Kummer, S. (2011). Organic farmers' experiments in Austria. Learning processes and resilience building in farmers' own experimentation activities. (Doctoral thesis), University of Natural Resources and Life Sciences, Vienna. Retrieved from http://permalink.obvsg.at/bok/AC07810093

Kummer, S., Milestad, R., Leitgeb, F., \& Vogl, C. R. (2012). Building Resilience through Farmers' Experiments in Organic Agriculture: Examples from Eastern Austria. Sustainable Agriculture Research, 1(2), 308-321. http://dx.doi.org/10.5539/sar.v1n2p308

Lawrence, D., Christodoulou, N., \& Whish, J. (2007). Designing better on-farm research in Australia using a participatory workshop process. Field Crops Research, 104(1-3), 157-164. http://dx.doi.org/10.1016/j.fcr.2007.03.018

Leitgeb, F., Funes-Monzote, F. R., Kummer, S., \& Vogl, C. R. (2011). Contribution of farmers' experiments and innovations to Cuba's agricultural innovation system. Renewable Agriculture and Food Systems, 26(04), 354-367. http://dx.doi.org/10.1017/s1742170511000251

Leitgeb, F., Kummer, S., Funes-Monzote, F. R., \& Vogl, C. R. (2014). Farmers' experiments in Cuba. Renewable 
Agriculture and Food Systems, 29(1), 48-64. https://doi.org/10.1017/S1742170512000336

Lyon, A., Bell, M. M., Gratton, C., \& Jackson, R. (2011). Farming without a recipe: Wisconsin graziers and new directions for agricultural science. Journal of Rural Studies, 27(4), 384-393.

http://dx.doi.org/10.1016/j.jrurstud.2011.04.002

Maat, H. (2011). The history and future of agricultural experiments. NJAS - Wageningen Journal of Life Sciences, 57(3-4), 187-195. http://dx.doi.org/10.1016/j.njas.2010.11.001

McKenzie, F. (2013). Farmer-driven Innovation in New South Wales, Australia. Australian Geographer, 44(1), 81-95. http://dx.doi.org/10.1080/00049182.2013.765349

Milestad, R., Dedieu, B., Darnhofer, I., \& Bellon, S. (2012). Farms and farmers facing change: The adaptive approach. In I. Darnhofer, D. Gibbon \& B. Dedieu (Eds.), Farming Systems Research into the 21st Century: The New Dynamic. Dordrecht: Springer.

Moeskops, B., Blake, F., Tort, M-C., \& Torremocha, E. (Eds.) (2014). Action Plan for Innovation and Learning, Brussels, Belgium: TP Organics.

Morgan, S. L., Marsden, T., Miele, M., \& Morley, A. (2010). Agricultural multifunctionality and farmers' entrepreneurial skills: A study of Tuscan and Welsh farmers. Journal of Rural Studies, 26(2), 116-129. http://dx.doi.org/10.1016/j.jrurstud.2009.09.002

Moschitz, H., Roep, D., Brunori, G., \& Tisenkopfs, T. (2015). Learning and Innovation Networks for Sustainable Agriculture: Processes of Co-evolution, Joint Reflection and Facilitation. The Journal of Agricultural Education and Extension, 21(1), 1-11. http://dx.doi.org/10.1080/1389224X.2014.991111

Oreszczyn, S., Lane, A., \& Carr, S. (2010). The role of networks of practice and webs of influencers on farmers' engagement with and learning about agricultural innovations. Journal of Rural Studies, 26, 404-417. http://dx.doi.org/10.1016/j.jrurstud.2010.03.003

Padel, S. (2001). Conversion to Organic Farming: A Typical Example of the Diffusion of an Innovation? Sociologia Ruralis, 41(1), 40-61. https://doi.org/10.1111/1467-9523.00169

Quiroz, C. (1999). Farmer experimentation in a Venezuelan Andean group. In G. Prain, S. Fujisaka \& M. D. Warren (Eds.), Biological and Cultural Diversity. The Role of Indigenous Agricultural Experimentation in Development (pp. 113-124). London: Intermediate Technology Publications.

Reij, C., \& Waters-Bayer, A. (2001a). An initial analysis of farmer innovators and their innovations. In C. Reij \& A. Waters-Bayer (Eds.), Farmer Innovation in Africa. A Source of Inspiration for Agricultural Development. London, UK: Earthscan.

Reij, C., \& Waters-Bayer, A. (Eds.). (2001b). Farmer Innovation in Africa: A Source of Inspiration for Agricultural Development. London: Earthscan.

Rivera, W. M., \& Sulaiman, R. V. (2009). Extension: object of reform, engine for innovation. Outlook on Agriculture, 38(3), 267-273. https://doi.org/10.5367/000000009789396810

Röling, N., \& Brouwers, J. (1999). Living local knowledge for sustainable development. In G. Prain, S. Fujisaka \& M. D. Warren (Eds.), Biological and Cultural Diversity. The Role of Indigenous Agricultural Experimentation in Development (pp. 147-157). London: Intermediate Technology Publications.

Saad, N. (2002). Farmer processes of experimentation and innovation. A review of the literature.: CGIAR systemwide program on participatory research and gender analysis.

Schneider, F., Fry, P., Ledermann, T., \& Rist, S. (2009). Social Learning Processes in Swiss Soil Protection - The 'From Farmer - To Farmer' Project. Human Ecology, 37, 475-489. http://dx.doi.org/10.1007/s10745-009-9262-1

Schut, M., Rodenburg, J., Klerkx, L., van Ast, A., \& Bastiaans, L. (2014). Systems approaches to innovation in crop protection. A systematic literature review. Crop Protection, 56, 98-108. http://dx.doi.org/10.1016/j.cropro.2013.11.017

Sewell, A. M., Gray, D. I., Blair, H. T., Kemp, P. D., Kenyon, P. R., Morris, S. T., \& Wood, B. A. (2014). Hatching new ideas about herb pastures: Learning together in a community of New Zealand farmers and agricultural scientists. Agricultural Systems, 125, 63-73. http://dx.doi.org/10.1016/j.agsy.2013.12.002

Stolzenbach, A. (1999). The indigenous concept of experimentation among Malian farmers. In G. Prain, S. Fujisaka \& M. D. Warren (Eds.), Biological and Cultural Diversity. The role of indigenous agricultural 
experimentation in development (pp. 163-171). London, UK: Intermediate Technology Publications.

Stuiver, M., Leeuwis, C., \& van der Ploeg, J. D. (2004). The Power of Experience: Farmers' Knowledge and Sustainable Innovations in Agriculture. In J. S. C. Wiskerke \& J. D. van der Ploeg (Eds.), Seeds of Transition. Essays on novelty production, niches and regimes in agriculture (pp. 93-118). Assen, The Netherlands: Royal van Gorcum.

Sturdy, J. D., Jewitt, G. P. W., \& Lorentz, S. A. (2008). Building an understanding of water use innovation adoption processes through farmer-driven experimentation. Physics and Chemistry of the Earth, 33, 859-873. http://dx.doi.org/10.1016/j.pce.2008.06.022

Sumberg, J., \& Okali, C. (1997). Farmers' Experiments: Creating Local Knowledge. London: Lynne Rienner Publishers, Inc.

Sumberg, J., Okali, C., \& Reece, D. (2003). Agricultural research in the face of diversity, local knowledge and the participation imperative: theoretical considerations. Agricultural Systems, 76(2), 739-753. https://doi.org/10.1016/S0308-521X(02)00153-1

Tambo, J. A., \& Wünscher, T. (2014). Identification and prioritization of farmers' innovations in northern Ghana. Renewable Agriculture and Food Systems, 30(06), 537-549. http://dx.doi.org/10.1017/s1742170514000374

Vaarst, M., Nissen, T. B., Østergaard, S., Klaas, I. C., Bennedsgaard, T. W., \& Christensen, J. (2007). Danish Stable Schools for Experiential Common Learning in Groups of Organic Dairy Farmers. Journal of Dairy Science, 90(5), 2543-2554. http://dx.doi.org/10.3168/jds.2006-607

Van Veldhuizen, L., Waters-Bayer, A., Ramírez, R., Johnson, D. A., \& Thompson, J. (Eds.). (1997). Farmers ${ }^{\prime}$ Research in Practice. Lessons from the Field. London, UK: Intermediate Technology Publications.

Vogl, C. R., Kummer, S., Leitgeb, F., Schunko, C., \& Aigner, M. (2015). Keeping the Actors in the Organic System Learning: The Role of Organic Farmers' Experiments. Sustainable Agriculture Research, 4(3), 136-144. http://dx.doi.org/10.5539/sar.v4n3p140

Wilbois, K.-P., Schwab, A., Fischer, H., Bachinger, J., Palme, S., Peters, H., \& Dongus, S. (Eds.). (2004). Leitfaden Praxisversuche. Frankfurt: Forschungsinstitut für biologischen Landbau [FiBL] Deutschland.

Wortmann, C. S., Christiansen, A. P., Glewen, K. L., Hejny, T. A., Mulliken, J., Peterson, J. M., ... Zoubek, G. L. (2005). Farmer research: Conventional experiences and guidelines for alternative agriculture and multi-functional agro-ecosystems. Renewable Agriculture and Food Systems, 20(4), 243-251. http://dx.doi.org/10.1079/raf2005110

\section{Copyrights}

Copyright for this article is retained by the author(s), with first publication rights granted to the journal.

This is an open-access article distributed under the terms and conditions of the Creative Commons Attribution license (http://creativecommons.org/licenses/by/3.0/). 